\title{
O Customer-Based Brand Equity do Complexo Turístico Itaipu: uma comparação entre as percepções dos visitantes do lado brasileiro e paraguaio
}

\section{The Customer-Based Brand Equity of Itaipu Tourist Complex: a comparison between perceptions of visitors from the Brazilian and Paraguayan side}

\author{
Rodrigo Chibiaqui (CHIBIAQUI, R.) ${ }^{*}$; \\ Eduardo Hack Neto (HACK NETO, E.) ${ }^{* * *}$
}

\begin{abstract}
RESUMO - Atrativos turísticos são normalmente analisados sob o enfoque da imagem, desconsiderando outras dimensões que compõem o Customer-Based Brand Equity (CBBE). O atrativo objeto desta pesquisa é a usina Itaipu Binacional, que possui complexos turísticos em suas duas margens (no Brasil e no Paraguai) e que apresentam diferença no número e no perfil dos visitantes. Neste trabalho se propôs mensurar o CBBE do Complexo Turístico Itaipu no lado brasileiro e no lado paraguaio por meio de uma pesquisa quantitativa, tipo survey, com 671 visitantes, através de um questionário baseado em escalas multidimensionais utilizadas em medições de destinos turísticos. Os dados foram coletados em 2016 e 2017 e analisados através de estatística descritiva e análise estratificada. Foi observado alto valor de marca para todos os itens do CBBE, sobretudo na dimensão conhecimento, e evidenciaram-se diferenças entre a percepção de marca dos visitantes nacionais (brasileiros e paraguaios) em relação aos estrangeiros, bem como entre a percepção dos viajantes experientes em relação aos esporádicos, principalmente nas dimensões conhecimento e qualidade percebida.
\end{abstract}

Palavras-chave: Turismo; Customer-based brand equity; Valor de marca; Atrativos turísticos; Gestão de marcas; Foz do Iguaçu; Hernandárias; Itaipu Binacional.

ABSTRACT - Tourist attractions are usually analyzed under the image approach, disregarding other dimensions that comprise the Customer-Based Brand Equity (CBBE). The attraction object of this research is Itaipu Binacional power plant, which has tourist complexes in its two sides (in Brazil and Paraguay) and it shows differences in the number and profile of visitors. This paper intended to measure the CBBE of the Itaipu Tourist Complex on the Brazilian and Paraguayan sides using a quantitative survey with 671 visitors, using a questionnaire based on multidimensional scales used in tourist destination measurements. Data were collected in 2016 and 2017 and analyzed through

* Formação: Graduação em Comunicação Social com ênfase em Publicidade e Propaganda; Especialização Lato Sensu (MBA) em Marketing e Vendas pela Fundação Getúlio Vargas (FVG); Mestrando no Programa de Pós-Graduação Stricto Sensu em Tecnologias, Gestão e Sustentabilidade (PPGTGS) da Universidade Estadual do Oeste do Paraná (UNIOESTE). Endereço físico para correspondência: Av. Tancredo Neves, 5057, casa 274. CEP 85.867-000. Foz do Iguaçu - Paraná - Brasil. E-mail: rodrigo@chibiaqui.com

\footnotetext{
** Formação: Graduação em Administração (Bacharelado) pela UNIFOZ; Especialização em Consultoria Empresarial pela UNIVEL e em Ecoturismo pela FECEA; Mestrado em Turismo e Hotelaria pela UNIVALI; Doutorado em Geografia pela UFPR e Universidad de Santiago de Compostela - Espanha (USC). Atividade profissional: Professor titular no Programa de Pós-Graduação Stricto Sensu em Tecnologias, Gestão e Sustentabilidade (PPGTGS) da Universidade Estadual do Oeste do Paraná (UNIOESTE). Empresário e sócio proprietário da EVERMAKE. Endereço físico para correspondência: Av. Iguaçu, 390 - Vila Yolanda. CEP 85853-230. Foz do Iguaçu - Paraná - Brasil. E-mail: professoreduardohack@gmail.com
} 
descriptive statistics and stratified analysis. A high brand value was observed for all CBBE items, especially in the awareness dimension, and differences between the brand perception of domestic (Brazilian and Paraguayan) and foreign visitors, as well as between the perception of experienced and sporadic travelers, mainly in awareness and perceived quality dimensions.

Key words: Tourism; Customer-based brand equity; Brand equity; Tourist attraction; Branding; Foz do Iguacu; Hernandarias; Itaipu Binacional. 


\section{INTRODUÇÃO}

O turismo é uma importante atividade sob os pontos de vista econômico e do desenvolvimento sustentável. O setor é responsável por 10\% do Produto Interno Bruto PIB mundial e emprega 1 em cada 10 pessoas no mundo (UNWTO, 2017). Além disso, é considerado uma atividade benéfica para a região onde ele é desenvolvido, pois possibilita promover o desenvolvimento com certa independência das políticas nacionais (DIAS; CASSAR, 2005) e tem amplo efeito multiplicador na economia do destino (VIGNATI, 2008). Essas características fazem com que cidades e regiões com potencial turístico almejem desenvolver o turismo, mas para isso uma gestão profissional e de excelência é necessária, pois a competitividade é cada vez mais imperativa em economias dependentes da atividade turística (SEABRA, 2017). Sendo assim, os destinos precisam encontrar vantagens e se diferenciarem para manterem-se na disputa (BARBACENA, 2012), pois antes de serem escolhidos pelos consumidores, serão comparados com diversos outros destinos com atributos semelhantes.

Nesta competição, uma marca de destino reconhecida pode ser um diferencial, pois evidencia características únicas e cria vantagem competitiva, mas apesar do papel da marca no processo de compra do turista estar em alta (BOO; BUSSER; BALOGLU, 2009) e da sua importância para empresas (SWARBROOKE; HORNER, 2002), seu estudo ainda é recente no turismo, sobretudo em atrativos. Conhecer o valor de marca dos atrativos é importante tanto para a gestão do destino, considerando que a dimensão 'Atrativos turísticos' é um dos enfoques do Estudo de Competitividade dos 65 Destinos Indutores $^{1}$ (HENZ; CRUZ, 2015), quanto para o atrativo, que a partir do diagnóstico pode ajustar o produto e as ações de marketing, visando melhores resultados para o atrativo e, consequentemente, para a localidade. Esta interdependência entre os valores de marca do destino e de seus atrativos foi comprovada no estudo de Gomes, Lopez e Molina (2015).

Entretanto, as pesquisas sobre destinos [e atrativos] turísticos consideravam somente o atributo imagem (BOO; BUSSER; BALOGLU, 2009; TELES 2011), mas recentemente percebeu-se que, no conceito de marca sob a perspectiva do consumidor,

\footnotetext{
${ }^{1}$ Programa realizado pelo Ministério do Turismo, o Serviço Brasileiro de Apoio às Micro e Pequenas Empresas (Sebrae Nacional) e a Fundação Getúlio Vargas,(FGV) desde 2007 até 2015.
} 
ou Customer Based Brand-Equity $(\mathrm{CBBE})^{2}$, a imagem é apenas uma de suas dimensões. Grande parte dos estudos de CBBE comprovam que a imagem é, de fato, o aspecto mais importante do valor de uma marca de destino, mas Konecnik e Gartner (2007) alertam que, sob a luz do brand equity ${ }^{3}$, esta não é a única dimensão a ser estudada. Estas dimensões da marca além da imagem, ficam evidentes no trabalho de Moraes e Gândara (2016), que destacam que os serviços turísticos devem ser ofertados nas condições divulgadas nos meios de comunicação, do contrário, perder-se-ia o encanto da atividade turística em face da incoerência entre a experiência [qualidade percebida] e um turismo imagético [imagem], ou seja, pouco adianta criar uma imagem de marca forte e não atender a expectativa gerada, pois irá gerar incoerência e, possivelmente, prejuízo à marca. Wong e Teoh (2015) também relataram em seus estudos uma relação de causaefeito entre atributos funcionais da competitividade [análogos à qualidade percebida] e o CBBE.

Portanto, neste trabalho buscou-se mensurar o valor de marca do atrativo turístico Itaipu Binacional, sob a perspectiva do consumidor, considerando todas as dimensões do CBBE sugeridas por Konecnik (2006): conhecimento, qualidade percebida, imagem e lealdade. O objeto de estudo [o atrativo turístico Itaipu Binacional], é operacionalizado através de dois Complexos Turísticos: um no lado brasileiro e outro no lado paraguaio da usina. A análise foi realizada através da demanda real, utilizando uma escala de CBBE adaptada para atrativos turísticos a partir de escalas validadas em destinos turísticos. De forma secundária, buscou-se avaliar a validade da escala, bem como identificar o perfil socioeconômico dos visitantes de ambos os lados, e, por fim, comparar os diagnósticos do lado brasileiro e paraguaio, identificando as similaridades e diferenças entre o valor de marca e o perfil do público visitante dos complexos turísticos de ambos os lados.

É importante destacar que a Itaipu Binacional, por ser compartilhada entre dois países, Brasil e Paraguai, é um atrativo ímpar, com estrutura de visitação distinta em seus Complexos Turísticos, situados um em cada país. Este trabalho, portanto, visa

2 Efeito diferencial que o conhecimento de uma marca exerce sobre a resposta de um consumidor (KOTLER; KELLER, 2012).

3 "Um conjunto de ativos e passivos ligados a uma marca, seu nome e seu símbolo, que se somam ou subtraem do valor proporcionado por um produto ou serviço para uma empresa e/ou para os consumidores dela" (AAKER, 1998, p. 16). 
também identificar possíveis diferenças na geração de valor de marca do mesmo atrativo sob pontos de vista diferentes.

\section{CUSTOMER-BASED BRAND EQUITY NO TURISMO}

Marcas diferenciam itens concorrentes, asseguram qualidade e proteção contra cópia e podem ter valor simbólico poderoso, o que implica em status e projeta o estilo de vida do consumidor (TUOMINEN, 1999). Muito mais que somente identificar o fabricante, a função de uma marca é transmitir o benefício principal do produto/serviço (ZARDO, 2003). Ela é um nome com poder de influenciar compradores, tornando-se um critério de compra (KAPFERER, 2008).

Para Yanaze (2006), a marca é tudo o que tem capacidade de se fixar na mente dos consumidores e induzir-lhes um sentimento de pertencimento e aproximação, além de um comportamento receptivo ao produto/serviço oferecido, além de ser um dos bens intangíveis da organização. Kotler e Keller (2012) vão além e afirmam que esta é um dos ativos intangíveis mais valiosos de uma empresa, pois inspiram confiança, geram fidelidade e simplificam a tomada de decisões dos compradores, sendo um meio poderoso de garantir vantagem competitiva a longo prazo.

Aaker (1998) postula que o brand equity gera valor não somente para a empresa, mas também para o consumidor. Logo, manter um alto valor de marca gera benefícios a curto e a longo prazo aos produtos, às organizações e aos consumidores. Wong e Teoh (2015) relataram em sua revisão bibliográfica que vários estudos observaram que um branding efetivo leva a uma melhor competitividade. Dedeoğlu et al. (2018) afirmam que, em destinos turísticos, a consciência da marca afeta positivamente a qualidade percebida e o valor percebido pelo cliente. Com isso, marcas consagradas podem praticar preços premium, suscitar lealdade dos clientes ou capturar maior interesse de investidores (KOTLER; KELLER, 2012). A abordagem para medição do brand equity pode ser financeira ou baseada no consumidor, e Lassar et al. (1995) afirmam que a percepção do consumidor é pré-requisito e gera impacto direto no valor financeiro da marca. Ou seja, o consumidor deve perceber o valor da marca para ter uma atitude positiva ou negativa em relação a ela. De acordo com Kotler e Keller (2012), este efeito 
diferencial que o conhecimento da marca pelo consumidor exerce sobre sua resposta à marca é chamado Customer-Based Brand Equity (CBBE).

Uma marca forte mostra-se útil para organizações de turismo, pois confere pretextos tangíveis a um serviço de natureza amplamente intangível, e traz benefícios a partir do ponto de vista do consumidor, que percebe o destino ou o atrativo com mais segurança, confiabilidade, qualidade e custo-benefício (SWARBROOKE; HORNER, 2002), e uma das características principais das marcas mais bem sucedidas mundialmente é que sua marca é monitorada constantemente pela administração (YANAZE, 2006), logo deduz-se que a mensuração do CBBE é de extrema importância para organizações que visam obter sucesso com suas marcas, sobretudo as de turismo.

De acordo com Vargas Neto (2003), dada a profusão de definições de Brand Equity, há uma grande quantidade de métodos para mensurá-lo. Os mais aceitos são o de Keller (1993), que o divide em dois componentes: lembrança da marca (formada pelo seu reconhecimento e recordação) e imagem da marca (formada pelos tipos, tendências, força e exclusividade das associações); e o de Aaker e Joachimsthaler (2007), que acreditam que o valor de marca deve ser estimado com base em quatro dimensões: conscientização, qualidade percebida, associações e fidelidade.

Vários estudos buscaram também um método de mensurar o CBBE. Um dos mais utilizados é a Escala Multidimensional de Brand Equity (MBE) de Yoo e Donthu (2001). Baseada em Aaker (1998) e Keller (1993), a escala foi proposta com quatro dimensões: lealdade à marca; qualidade percebida; lembrança de marca; e associações da marca, mas os resultados do estudo mostraram que as dimensões lembrança de marca e associações de marca deveriam ser unidas. Vargas Neto (2003) corrobora que lembrança e associações de marca constituem uma única dimensão, que seria análoga à dimensão conhecimento de marca, proposta por Keller (1993), e que é resultado da lembrança e da imagem (associações) da marca.

Já os primeiros modelos para mensurar o CBBE de destinos turísticos foram propostos por Konecnik (2006) e Boo (2006), depois adaptado e utilizado por Konecnik e Gartner (2007), Boo, Busser e Baloglu (2009), Pike et al. (2010), Teles (2011), Yuwo, Ford e Purwanegara (2013), Kashif, Samsi e Sarifuddin (2015), Sibireva (2014), Zeytonli, Dana e Madadi (2015) e Gomez, Lopez e Molina (2015). 
Há diferenças sutis nos estudos de Boo (2006) e Konecnik (2006). Enquanto este estudou a percepção de turistas alemães e croatas que visitaram a Eslovenia, aquele estudou a percepção de turistas americanos em destinos de jogos (gamblers). Konecnik (2006) utilizou quatro dimensões em seus estudos: awareness, ou conhecimento de marca; image, ou imagem de marca; quality, ou qualidade percebida pelo consumidor; e loyalty, ou lealdade do consumidor. Já Boo (2006), além das dimensões utilizadas por Konecnik (2006), inseriu a dimensão value, relacionada ao preço pago pelo consumidor. Entretanto, o resultado de seu estudo indicou a necessidade de mesclar as dimensões quality e image, formando dimensão chamada de experience.

Uma das restrições em relação a mensuração do CBBE é que ainda não há um modelo amplamente aceito para a medição (DEDEOĞLU et al. 2018). Cada estudo adapta o modelo às características próprias do destino/atrativo. Seguindo esta premissa, Chibiaqui e Hack Neto (2018) propuseram uma escala para mensuração de CBBE de atrativo turístico técnico-científico, utilizada no presente estudo, baseado em escalas anteriormente utilizadas em mensuração de CBBE de destinos turísticos, sobretudo nos modelos de Konecnik (2006) e Boo (2006).

\section{METODOLOGIA}

Utilizou-se o método survey, que possibilita a descrição quantitativa a partir de uma amostra (CRESWELL, 2007), e o instrumento questionário, que apresenta menor custo e ampla cobertura (MALHOTRA, 2004). Traduzido do português para espanhol e inglês, este era composto por três seções: (1) Apresentação; (2) CBBE, com 30 afirmações sobre a percepção de marca do CTI, as quais os visitantes assinalavam o nível de concordância em uma escala de Likert; e (3) Perfil do entrevistado.

O estudo baseou-se em dados obtidos previamente por Chibiaqui e Hack Neto (2018) em pesquisas isoladas no lado paraguaio do CTI, em 2016, e no lado brasileiro em 2017, utilizando uma escala adaptada a partir de instrumentos utilizados em estudos de CBBE de destinos, detalhada no Quadro 1, com itens ajustados de acordo com as necessidades do consumidor de atrativos, tendo como base autores como Keller (1993) e Aaker (1998) no tema Brand Equity, Yoo e Donthu (2001), pois propuseram a escala 
MBE, e Konecnik (2006) e Boo (2006), pioneiros nos estudos de CBBE de destinos turísticos, Pike et al. (2010) e Kashif, Samsi e Sarifuddin (2015) pois são estudos recentes que propuseram adaptações nos questionários, e Teles (2011), que estudou o CBBE em destino nacional, traduzindo e adaptando o questionário para a realidade brasileira.

QUADRO 1 - DIMENSÕES E ITENS DO CBBE PARA ATRATIVOS TURÍSTICOS

\begin{tabular}{|c|c|c|}
\hline Dimensões & Itens & Literatura \\
\hline $\begin{array}{l}\text { Conheci- } \\
\text { mento de } \\
\text { marca } \\
(\mathrm{CM})\end{array}$ & $\begin{array}{l}\text { CM1: Este atrativo tem um bom nome e reputação. } \\
\text { CM2: Este atrativo é muito famoso. } \\
\text { CM3: Algumas características deste atrativo vêm rapidamente a minha } \\
\text { mente. } \\
\text { CM4: Quando eu penso em turismo técnico-científico, este atrativo vem } \\
\text { rapidamente a minha mente, } \\
\text { CM5: Eu consigo me lembrar da logomarca da Itaipu. }\end{array}$ & \multirow{4}{*}{$\begin{array}{l}\text { Keller (1993); } \\
\text { Aaker (1998); Yoo } \\
\text { e Donthu (2001); } \\
\text { Konecnik (2006); } \\
\text { Boo (2006); } \\
\text { Konecnick e } \\
\text { Gartner (2007); } \\
\text { Boo, Busser e } \\
\text { Baloglu (2009); } \\
\text { Pike et al.(2010); } \\
\text { Teles (2011); } \\
\text { Kashif, Samsi e } \\
\text { Sarifuddin. (2015). }\end{array}$} \\
\hline $\begin{array}{l}\text { Qualidade } \\
\text { Percebida } \\
\quad \text { (QP) }\end{array}$ & $\begin{array}{l}\text { QP1: Este atrativo apresenta serviços de ótima qualidade. } \\
\text { QP2: Este atrativo oferece boas experiências. } \\
\text { QP3: Eu posso esperar ótimo desempenho dos passeios deste atrativo. } \\
\text { QP4: Este atrativo apresenta melhor desempenho que atrativos } \\
\text { similares. } \\
\text { QP5: Este atrativo tem ótima infraestrutura turística. } \\
\text { QP6: A limpeza desse atrativo é ótima. } \\
\text { QP7: Este atrativo é muito seguro. } \\
\text { QP8: Este atrativo oferece boas opções de gastronomia. }\end{array}$ & \\
\hline $\begin{array}{l}\text { Imagem } \\
\text { de Marca } \\
\quad(\mathrm{IM})\end{array}$ & $\begin{array}{l}\text { IM1: O Complexo Turístico Itaipu possui perfil de instituição inovadora. } \\
\text { IM2: Este atrativo apresenta bom entretenimento. } \\
\text { IM3: Este atrativo proporciona novos conhecimentos. } \\
\text { IM4: Este atrativo tem atmosfera empolgante. } \\
\text { IM5: O Complexo Turístico Itaipu tem um ambiente agradável. } \\
\text { IM6: Este atrativo apresenta ambiente relaxante. } \\
\text { IM7: O Complexo Turístico Itaipu tem bons projetos sociais e } \\
\text { ambientais. } \\
\text { IM8: Os colaboradores são simpáticos. } \\
\text { IM9: O Complexo Turístico Itaipu tem boa localização e fácil acesso. } \\
\text { IM10: Este atrativo se encaixa na minha personalidade. } \\
\text { IM11: Meus amigos vão pensar bem de mim se souberem que visitei } \\
\text { Itaipu. } \\
\text { IM12: A imagem deste atrativo é coerente com minha autoimagem. } \\
\text { IM13: Visitar este atrativo reflete quem eu sou. }\end{array}$ & \\
\hline $\begin{array}{l}\text { Lealdade } \\
\text { de Marca } \\
\qquad(\mathrm{LM})\end{array}$ & $\begin{array}{l}\text { LM1: Eu gostaria de voltar a visitar este atrativo no futuro. } \\
\text { LM2: Pretendo recomendar este atrativo para meus amigos. } \\
\text { LM3: Itaipu proporciona mais benefícios que outros atrativos similares. } \\
\text { LM4: Itaipu é um dos meus atrativos preferidos para visitar. }\end{array}$ & \\
\hline
\end{tabular}

FONTE: Chibiaqui e Hack Neto, 2018.

As amostras foram calculadas de acordo com Barbetta (2011). No lado paraguaio, foi considerado como universo a média mensal de turistas que realizaram o passeio Visita Turística entre maio e junho de 2015: 5.661 pessoas, sendo 68\% 
paraguaios e $32 \%$ estrangeiros. A pesquisa foi realizada entre 24 de maio até 13 de junho de 2016 com 309 entrevistados. Os questionários com valores nulos nas questões referentes ao CBBE foram descartados, restando 286 válidos. A confiabilidade da amostra ficou em 95\% e o erro amostral tolerável em 5,3\%, e atingiu distribuição semelhante ao universo, com $65 \%$ paraguaios e $35 \%$ estrangeiros.

Realizou-se o pré-teste em duas fases: primeiro com duas pessoas nativas nos idiomas dos questionários, para verificar o entendimento dos termos, depois no local da pesquisa, com onze respondentes, onde foi possível observar o melhor local, abordagem e tempo necessário para o preenchimento do questionário. No Paraguai, a coleta dos dados foi realizada no Laboratório de hidroinformática, onde o CTI lado paraguaio operava temporariamente, enquanto o Centro de Recepção de Visitantes passava por reformas. Os turistas eram abordados e os questionários entregues em prancheta e preenchidos antes de iniciarem o passeio.

No lado brasileiro, considerou-se como universo a média mensal de turistas entre maio e junho de 2016: 20.942,5, sendo 89,75\% brasileiros e 10,25\% estrangeiros. A pesquisa foi realizada entre maio e junho de 2017 com 448 entrevistados. Os mesmos procedimentos de filtragem realizados na pesquisa do lado paraguaio foram realizados, restando 385 válidos. A amostra atingiu confiabilidade de 95\%, erro amostral tolerável de 5,3\%, e distribuição semelhante ao universo, com 87,27\% brasileiros e 11,69\% estrangeiros. No Brasil, a coleta dos dados foi realizada no Centro de Recepção de Visitantes, antes dos turistas iniciarem o passeio, tal como a pesquisa no lado paraguaio.

Os dados foram analisados através de estatística descritiva, que visa sintetizar os dados da amostra, e da análise estratificada, que divide a amostra em subgrupos (PEREIRA, 2013), utilizando os softwares de edição de planilhas, onde foram tratados, filtrados e cruzados para identificar média, desvio padrão e sensibilidade entre variáveis do perfil, bem como comparações entre a amostra obtida no lado paraguaio e no lado brasileiro. A confiabilidade interna das subescalas foram verificadas com software SPSS, através do coeficiente Alpha de Cronbach, que de acordo com Hair et al. (2005), deve apresentar valor superior a 0,70 para ser considerado aceitável. 


\section{COMPLEXO TURÍSTICO ITAIPU: OBJETO DE ESTUDO}

A Itaipu Binacional é uma usina hidrelétrica localizada na fronteira entre Brasil e Paraguai, considerada uma das 7 maravilhas do mundo moderno (ITAIPU, 2019) e a maior usina do mundo em geração de energia (SÓRIA, 2012). Desde 1977, durante as obras, a usina já atraía visitantes, tanto no lado brasileiro, em Foz do Iguaçu, quanto no paraguaio, em Hernandárias (CURY; RODRIGUEZ, 2011; ITAIPU, 2015).

O município brasileiro onde a usina fica localizada, Foz do Iguaçu, é uma cidade turística reconhecida internacionalmente, com atrativos que contemplam todas as hierarquias da Organização Mundial do Turismo - OMT/CICATUR, dos quais destacam-se as Cataratas do Iguaçu, o Parque Nacional do Iguaçu e a Itaipu Binacional, e possui oferta turística e estrutura condizente com sua atratividade (GÂNDARA; HACK NETO; MANOSSO, 2014). Já Hernandárias, o município paraguaio que sedia a usina, não tem outro atrativo de grande porte, mas é vizinha de Ciudad del Este, o maior centro comercial do [país] Paraguai, com lojas e cassinos que atraem visitantes do Brasil e Argentina, e fica a $122 \mathrm{~km}$ de Santa Rita, sede de uma feira de agronegócios que atrai aproximadamente 220 mil visitantes por ano (LA NACIÓN, 2015). No Inventário Turístico do Brasil (LIMA, 2011), a Itaipu Binacional é classificada em 'realizações técnicas e científicas contemporâneas', e no Plan Maestro de Turismo de 2012 do Paraguai, em 'recursos turísticos culturales', subitem 'tecnologicos”. Em ambos países, o CTI tem outras estruturas turísticas, como planetário e observatório astronômico, viveiros, museus, entre outros.

Para Sória (2012), o fato de a usina de Itaipu ter sido construída na região das Cataratas do Iguaçu, e da grande atratividade que a usina exerce, recebendo, de 1977 a 2016, cerca de 20 milhões de turistas, contribui para a maior permanência de turistas na região. Ainda segundo o autor, a vocação para o turismo, que já acontecia desde antes da inauguração da obra, ficou mais evidente após a revisão da missão da Itaipu, em 2003, que incluiu o 'desenvolvimento regional, turístico e tecnológico do Brasil e do Paraguai', tornando o turismo atividade chave na empresa, com o objetivo de potencializar o desenvolvimento regional sustentável.

A escolha do Complexo Turístico Itaipu (CTI) como objeto de estudo deve-se ao fato da usina ser considerada um produto com alto nível de atratividade segundo a 
classificação OMT/CICATUR; de ser um atrativo técnico-científico, pouco usual em ambos países; de ter em sua missão empresarial o desenvolvimento regional através do turismo (SÓRIA, 2012); e estar bem estruturada para receber o turista, com um complexo turístico em cada uma de suas margens (brasileira e paraguaia).

\section{PERFIL DOS VISITANTES DO CTI}

Quanto a Identificação do Perfil Socioeconômico dos visitantes, tanto o CTI lado paraguaio quanto o lado brasileiro recebem visitantes com perfil heterogêneo, e cujas principais características socioeconômicas da amostra foram evidenciadas na Tabela 1 .

TABELA 1 - CARACTERIZAÇÃO DA AMOSTRA

\begin{tabular}{|c|c|c|c|c|}
\hline \multirow[b]{2}{*}{ Variável } & \multicolumn{2}{|c|}{ Lado paraguaio } & \multicolumn{2}{|c|}{ Lado brasileiro } \\
\hline & Principal índice & Frequência & Principal índice & Frequência \\
\hline País & Paraguai & $185(64,69 \%)$ & Brasil & $336(87,27 \%)$ \\
\hline Concentração da residência & Urbana & $233(81,47 \%)$ & Urbana & $276(71,67 \%)$ \\
\hline Vezes que visitou Itaipu & Primeira vez & $178(62,24)$ & Primeira vez & $274(71,17 \%)$ \\
\hline $\begin{array}{l}\text { Visitou outros atrativos } \\
\text { técnico-científicos }\end{array}$ & Não & $203(70,98)$ & Não & $229(59,48 \%)$ \\
\hline Tipo de viagem & Com a família & $101(35,51)$ & Com a família & $189(49,09 \%)$ \\
\hline Permanência no destino & Menos de um dia & $123(43,01)$ & Entre 1 e 3 dias & $153(39,74 \%)$ \\
\hline Tempo que ficará em Itaipu & Algumas horas & $206(72,03)$ & Algumas horas & $288(74,81 \%)$ \\
\hline Gênero & Feminino & $143(46,50)$ & Feminino & $181(47,01 \%)$ \\
\hline Idade & Até 24 anos & $135(47,20)$ & Entre 25 e 34 anos & $130(33,77 \%)$ \\
\hline Escolaridade & $\begin{array}{l}\text { Superior } \\
\text { completo }\end{array}$ & $75(26,22)$ & Superior completo & $110(20,57 \%)$ \\
\hline Motivação da visita & Qualidade & $135(47,20)$ & Qualidade & $184(47,79 \%)$ \\
\hline Viajou para outros países & Sim & $188(65,73)$ & Sim & $254(65,97 \%)$ \\
\hline Viajou para quantos países & Dois países & $47(16,43)$ & Um a três & $126(32,73 \%)$ \\
\hline Estado civil & Solteiro & $195(68,18)$ & Casado & $169(43,90 \%)$ \\
\hline Renda familiar mensal & Até 500 dólares & $67(23,43)$ & Acima de $2.000 \mathrm{U \$}$ & $194(50,39 \%)$ \\
\hline
\end{tabular}

FONTE: análise dos dados da pesquisa, 2018.

Em ambos os lados, a maioria dos respondentes (aproximadamente 88\%) era oriunda do Paraguai, Brasil ou Argentina, e menos de 10\% residia nas cidades vizinhas, logo podem ser considerados visitantes. No lado brasileiro, aproximadamente $35 \%$ já 
conhecia a usina, enquanto no lado paraguaio este número sobe para aproximadamente $35 \%$, indicando fidelidade e força da marca (KOTLER; KELLER, 2012). Uma grande parte (aproximadamente 65\%) já havia viajado para outros países, mas em sua maioria próximos da região de residência, sugerindo um público com pouca experiência de consumo em países mais desenvolvidos.

Em ambos os lados (brasileiro e paraguaio) a viagem ocorreu prioritariamente com família. Em relação ao tempo de viagem, o visitante do lado paraguaio foi caracterizado como excursionista, considerando que a maior parte do público permanecia menos de um dia no destino. Já os visitantes do lado brasileiro mencionaram permanecer até 3 dias no destino. Este dado demonstrou que, principalmente no Paraguai, dever-se-ia implementar estratégias para aumentar o tempo de permanência, para que a região aproveitasse melhor os benefícios do turismo.

A qualidade foi o fator motivador para aproximadamente $47 \%$ do público ir à usina. Em relação à renda familiar mensal, no lado paraguaio a maioria $(45,46 \%)$ mencionou ganhar até 1.000 dólares, já no lado brasileiro mais de metade dos visitantes apresentaram renda acima de 2.000 dólares, evidenciando uma diferença de público que poderia estar relacionada com a renda média do país, ou então com o público atraído pela gratuidade no lado paraguaio, uma vez que a visita não é cobrada neste lado da usina, em contraste com a visitação no lado brasileiro, que é paga.

Destaca-se que aproximadamente $75 \%$ passariam apenas algumas horas em Itaipu. Este dado mostrou ser possível ampliar o tempo de visitação em Itaipu, pois a usina tem atração para pelo menos um dia inteiro de atividades, tanto no lado brasileiro quanto no lado paraguaio. Desta forma, aumentaria o tempo de permanência no destino, fazendo com que a região aproveitasse melhor os benefícios do turismo.

\section{CBBE DO COMPLEXO TURÍSTICO ITAIPU}

De acordo com os critérios propostos neste trabalho, o CBBE de um atrativo turístico é composto por 4 dimensões, formadas por itens que recebiam notas em uma escala de Likert de 5 pontos. Quanto maior o grau de concordância, maior a pontuação do item e, consequentemente, da dimensão. A pontuação do CBBE do CTI lado 
paraguaio, calculada através de uma média simples entre a pontuação das quatro dimensões, ficou em 4,23 dos 5 pontos possíveis, sendo que verificou-se haver uma uniformidade na nota das dimensões, que variaram de 4,21 na dimensão mais mal avaliada, Conhecimento de Marca, a 4,24 em Lealdade de Marca, dimensão mais bem avaliada. No lado brasileiro, a pontuação das dimensões ficou em 4,04, onde também observou-se uniformidade nas notas das dimensões, que variaram de 3,94 na dimensão mais mal avaliada, Lealdade, a 4,09 em Imagem, dimensão mais bem avaliada, como pode ser observado na Tabela 2.

TABELA 2 - COMPARAÇÃO DO CBBE DO LADO BRASILEIRO E PARAGUAIO DO CTI

\begin{tabular}{|c|c|c|c|c|c|}
\hline \multirow[t]{2}{*}{ Dimensão } & \multicolumn{2}{|c|}{ Lado brasileiro } & \multicolumn{2}{|c|}{ Lado paraguaio } & \multirow{2}{*}{$\begin{array}{l}\text { Geral } \\
\text { Média (desv. } \\
\text { padrão) }\end{array}$} \\
\hline & $\begin{array}{l}\text { Média (desv. } \\
\text { padrão) }\end{array}$ & $\begin{array}{l}\text { Alpha de } \\
\text { Cronbach }\end{array}$ & $\begin{array}{l}\text { Média (desv. } \\
\text { padrão) }\end{array}$ & $\begin{array}{l}\text { Alpha de } \\
\text { Cronbach }\end{array}$ & \\
\hline $\begin{array}{l}\text { Conhecimento de } \\
\text { Marca }(\mathrm{CM})\end{array}$ & $4,00(0,70)$ & 0,67 & $4,21(0,71)$ & 0,69 & $4,09(0,71)$ \\
\hline $\begin{array}{l}\text { Qualidade Percebida } \\
\text { (QP) }\end{array}$ & $4,03(0,65)$ & 0,86 & $4,23(0,55)$ & 0,79 & $4,12(0,62)$ \\
\hline $\begin{array}{l}\text { Imagem de Marca } \\
\text { (IM) }\end{array}$ & $4,09(0,64)$ & 0,90 & $4,22(0,61)$ & 0,87 & $4,15(0,63)$ \\
\hline $\begin{array}{l}\text { Lealdade de Marca } \\
\text { (LM) }\end{array}$ & $3,94(0,77)$ & 0,81 & $4,24(0,73)$ & 0,79 & $4,07(0,77)$ \\
\hline $\begin{array}{l}\text { Customer-Based } \\
\text { Brand Equity } \\
(\mathrm{CBBE})\end{array}$ & $4,04(0,59)$ & - & $4,23(0,55)$ & - & $4,12(0,58)$ \\
\hline
\end{tabular}

FONTE: Análise dos dados da pesquisa, 2018.

Em todas as amostras, a confiabilidade interna da escala, medida pelo alfa de Cronbach, teve ótimo desempenho, acima do recomendado por Hair et al. (2005) em praticamente todas as dimensões avaliadas, com exceção do Conhecimento de Marca.

Ao avaliar cada item das dimensões, conforme detalhado na Tabela 3, observa-se os itens que tiveram melhor ou pior desempenho. Na dimensão Conhecimento de Marca, tanto na amostra do lado brasileiro quanto no lado paraguaio, os itens Lembrança da Logomarca (CM5) e o Share of Mind do atrativo (CM4) foram os mais mal avaliados, enquanto o item Fama (CM2) e o Fama e Reputação do atrativo (CM1) obtiveram as melhores pontuações da dimensão, sendo que este item obteve a maior pontuação de todo o CBBE do lado brasileiro. Observou-se ainda que no item CM5 houve um alto desvio padrão e baixa correlação com os demais itens do construto, que foi o único com 
Alfa de Cronbach abaixo do padrão aceitável $(0,7)$. No teste de consistência interna observou-se que, removendo este item (CM5), o Alfa de Cronbach seria elevado para o padrão aceitável.

Na dimensão Qualidade Percebida, o item limpeza e desempenho dos passeios foi bem avaliado no lado brasileiro e paraguaio, enquanto opções gastronômicas foi o pior item em ambos os lados. No Paraguai, a má pontuação foi compreensível, pois o Centro de Recepções de Visitantes estava em reforma, sem oferecer opções de alimentação. Já no lado brasileiro, conviria avaliar a qualidade e divulgação das opções de alimentação, que são oferecidas em diversos pontos da visita.

TABELA 3 - COMPARAÇÃO DOS ITENS DO CBBE DO LADO BRASILEIRO E PARAGUAIO DO CTI

\begin{tabular}{|c|c|c|c|c|}
\hline Dimensão & Item & $\begin{array}{c}\text { Lado brasileiro } \\
\text { média (desvio padrão) }\end{array}$ & $\begin{array}{c}\text { Lado paraguaio } \\
\text { média (desvio padrão) }\end{array}$ & $\begin{array}{c}\text { Geral } \\
\text { média (desvio padrão) }\end{array}$ \\
\hline \multirow{5}{*}{$\begin{array}{l}\text { Conhecimento de } \\
\text { marca }(\mathrm{CM})\end{array}$} & CM1 & $4,58(0,78)$ & $4,58(0,78)$ & $4,58(0,78)$ \\
\hline & $\mathrm{CM} 2$ & $4,50(0,89)$ & $4,50(0,86)$ & $4,50(0,88)$ \\
\hline & CM3 & $4,08(0,94)$ & $4,07(0,98)$ & $4,08(0,96)$ \\
\hline & CM4 & $3,79(1,03)$ & $3,95(1,09)$ & $3,86(1,06)$ \\
\hline & CM5 & $3,05(1,48)$ & $3,95(1,43)$ & $3,43(1,52)$ \\
\hline \multirow{8}{*}{$\begin{array}{c}\text { Qualidade } \\
\text { percebida }(\mathrm{QP})\end{array}$} & QP1 & $3,97(0,99)$ & $4,33(0,88)$ & $4,13(0,96)$ \\
\hline & QP2 & $4,17(0,92)$ & $4,39(0,83)$ & $4,26(0,89)$ \\
\hline & QP3 & $4,38(0,86)$ & $4,48(0,83)$ & $4,42(0,85)$ \\
\hline & QP4 & $3,68(0,89)$ & $3,99(0,92)$ & $3,81(0,92)$ \\
\hline & QP5 & $4,28(0,92)$ & $4,45(0,78)$ & $4,35(0,87)$ \\
\hline & QP6 & $4,44(0,81)$ & $4,49(0,85)$ & $4,46(0,83)$ \\
\hline & QP7 & $4,14(0,94)$ & $4,34(0,83)$ & $4,22(0,90)$ \\
\hline & QP8 & $3,19(0,89)$ & $3,41(0,97)$ & $3,28(0,93)$ \\
\hline \multirow{10}{*}{$\begin{array}{l}\text { Imagem de marca } \\
\text { (IM) }\end{array}$} & IM1 & $4,02(0,93)$ & $4,06(0,87)$ & $4,04(0,90)$ \\
\hline & IM2 & $4,02(0,93)$ & $4,28(0,88)$ & $4,13(0,92)$ \\
\hline & IM3 & $4,46(0,77)$ & $4,63(0,66)$ & $4,53(0,73)$ \\
\hline & IM4 & $4,14(0,93)$ & $4,24(0,95)$ & $4,18(0,94)$ \\
\hline & IM5 & $4,45(0,79)$ & $4,39(0,90)$ & $4,42(0,84)$ \\
\hline & IM6 & $4,11(0,93)$ & $4,48(0,80)$ & $4,27(0,90)$ \\
\hline & IM7 & $4,02(1,00)$ & $4,22(0,96)$ & $4,10(0,99)$ \\
\hline & IM8 & $4,46(0,84)$ & $4,56(0,86)$ & $4,50(0,85)$ \\
\hline & IM9 & $4,24(0,98)$ & $4,15(1,09)$ & $4,20(1,03)$ \\
\hline & IM10 & $4,03(1,01)$ & $4,10(0,96)$ & $4,06(0,99)$ \\
\hline
\end{tabular}




\begin{tabular}{ccccc}
\hline Dimensão & Item & $\begin{array}{c}\text { Lado brasileiro } \\
\text { média (desvio padrão) }\end{array}$ & $\begin{array}{c}\text { Lado paraguaio } \\
\text { média (desvio padrão) }\end{array}$ & $\begin{array}{c}\text { Geral } \\
\text { média (desvio padrão) }\end{array}$ \\
\hline & IM11 & $3,92(1,11)$ & $4,18(1,04)$ & $4,03(1,09)$ \\
\cline { 2 - 5 } & IM12 & $3,82(1,04)$ & $3,94(1,05)$ & $3,87(1,04)$ \\
\cline { 2 - 5 } $\begin{array}{c}\text { Lealdade de marca } \\
(\mathrm{LM})\end{array}$ & IM13 & $3,52(1,09)$ & $3,66(1,20)$ & $3,58(1,14)$ \\
\cline { 2 - 5 } & LM1 & $4,16(1,03)$ & $4,48(0,90)$ & $4,30(0,99)$ \\
\cline { 2 - 5 } & LM3 & $3,43(0,86)$ & $4,57(0,76)$ & $4,49(0,82)$ \\
\cline { 2 - 5 } & LM4 & $3,43(1,05)$ & $4,03(0,96)$ & $3,86(0,95)$ \\
\hline
\end{tabular}

FONTE: análise dos dados da pesquisa, 2018.

$\mathrm{Na}$ dimensão Imagem de marca, houve diferença entre os itens baseados em Konecnick (2006), IM1 a IM9, fundamentados nos atributos da empresa e aspectos funcionais do atrativo, que foram melhores avaliados, e os atributos utilizados por Boo (2006), IM10 a IM13, focados no alinhamento entre a autoimagem do turista e a imagem que ele tem do atrativo, e que foram pior avaliados. Os itens IM3 e IM8 que se relacionaram respectivamente sobre o atrativo proporcionar novos conhecimentos e a simpatia dos atendentes foram os mais bem avaliados nesta dimensão, com destaque para o item IM3, que foi o melhor avaliado em todo o CBBE do lado paraguaio. Já a afirmação "este atrativo reflete quem eu sou” (IM13) foi a pior avaliada tanto no lado brasileiro quanto no lado paraguaio.

Em Lealdade de marca, o item LM4, um dos atrativos preferidos para visitar, obteve a menor pontuação, enquanto o item LM2, pretendo recomendar a amigos, foi uma das maiores pontuações do CBBE.

De maneira geral, verificou-se que as diferenças do perfil do público afetaram pouco a percepção de marca do atrativo. Porém, algumas observações se fazem pertinentes, pois demonstram certo grau de relação com o valor de marca percebido, conforme Tabelas 4 e 5. Em ambos os lados, percebeu-se que turistas que não haviam visitado outros países ou que visitaram menos de 3 países avaliaram a marca do atrativo de maneira mais positiva em todas as dimensões, enquanto pessoas que visitaram quatro ou mais países avaliaram com menor pontuação todas as dimensões, especialmente Conhecimento de Marca e Lealdade à Marca. Adicionalmente, segmentou-se os respondentes que moram ou já visitaram pelo menos um país avançado economicamente, segundo critério do IMF (2017). Percebeu-se significativa diferença na análise, principalmente no item Qualidade Percebida, o que sugere que visitantes 
mais experientes, possivelmente por terem mais referências de bons atrativos, acabam sendo mais criteriosos ao avaliarem a qualidade dos atrativos.

TABELA 4 - CBBE DO LADO BRASILEIRO ESTRATIFICADO COM BASE NAS PRINCIPAIS VARIÁVEIS

\begin{tabular}{llccccc}
\hline \multicolumn{1}{c}{ Variável } & Índice (Respondentes) & CM & QP & IM & LM & CBBE \\
\hline Países visitados & Quatro ou mais & 3,84 & 3,86 & 4,00 & 3,68 & 3,82 \\
& Um a três & 4,04 & 4,05 & 4,13 & 4,18 & 3,91 \\
& Nenhum & 4,10 & 4,00 & 4,19 & 4,47 & 4,06 \\
\hline Mora ou visitou países & Sim (113) & 3,89 & 3,85 & 4,01 & 3,78 & 3,92 \\
avançados economicamente & Não (243) & 4,06 & 4,13 & 4,15 & 4,01 & 4,11 \\
\hline País de residência & Brasil & 4,07 & 4,06 & 4,12 & 3,96 & 4,07 \\
& Argentina & 3,60 & 3,88 & 3,85 & 3,69 & 3,80 \\
& Outros & 3,40 & 3,75 & 3,88 & 3,77 & 3,75 \\
\hline Vezes que visitou Itaipu & Primeira vez & 3,90 & 3,95 & 4,06 & 3,88 & 3,98 \\
& Duas ou mais vezes & 4,30 & 4,27 & 4,19 & 4,11 & 4,22 \\
\hline Motivação da visita & Qualidade & 4,13 & 4,17 & 4,24 & 4,16 & 4,19 \\
& Proximidade & 3,79 & 3,88 & 3,81 & 3,56 & 3,79 \\
& Gratuidade & 4,28 & 3,71 & 3,93 & 4,13 & 3,96 \\
& Outros & 3,92 & 3,96 & 4,06 & 3,78 & 3,97 \\
\hline
\end{tabular}

FONTE: Análise dos dados da pesquisa, 2018.

TABELA 5 - CBBE DO LADO PARAGUAIO ESTRATIFICADO COM BASE NAS PRINCIPAIS VARIÁVEIS

\begin{tabular}{llllllc}
\hline \multicolumn{1}{c}{ Variável } & \multicolumn{1}{c}{ Índice } & CM & QP & IM & LM & CBBE \\
\hline Países visitados & Quatro ou mais & 3,61 & 3,84 & 3,88 & 3,68 & 3,79 \\
& Um a três & 4,24 & 4,21 & 4,18 & 4,18 & 4,20 \\
& Nenhum & 4,42 & 4,43 & 3,48 & 4,47 & 4,41 \\
\hline Mora ou visitou países & Sim (27) & 4,24 & 4,16 & 4,18 & 4,16 & 4,18 \\
avançados economicamente & Não (219) & 4,21 & 4,25 & 4,22 & 4,25 & 4,23 \\
\hline País de residência & Brasil & 4,09 & 4,31 & 4,34 & 4,28 & 4,28 \\
& Paraguai & 4,45 & 4,36 & 4,32 & 4,40 & 4,36 \\
& Argentina & 3,53 & 3,89 & 3,90 & 3,76 & 3,82 \\
& Outros & 3,67 & 3,81 & 3,87 & 3,79 & 3,81 \\
\hline Vezes que visitou Itaipu & Primeira vez & 4,07 & 4,17 & 4,14 & 4,14 & 4,14 \\
& Duas ou mais vezes & 4,45 & 4,34 & 4,33 & 4,38 & 4,36 \\
\hline Motivação da visita & Qualidade & 4,33 & 4,38 & 4,31 & 4,44 & 4,35 \\
& Proximidade & 3,96 & 4,10 & 4,12 & 3,98 & 4,07 \\
& Gratuidade & 4,15 & 4,08 & 4,12 & 4,10 & 4,11 \\
& Outros & 4,16 & 4,12 & 4,16 & 4,10 & 4,14 \\
\hline
\end{tabular}

FONTE: Análise dos dados da pesquisa, 2018.

O país de residência também mostrou afetar a percepção de marca. Moradores do Brasil e do Paraguai, países onde está localizada a usina, avaliaram melhor todos os itens do CBBE. Já os residentes em outros países avaliaram com notas menores, 
especialmente no item Conhecimento de Marca. Os residentes na Argentina, apesar de estarem geograficamente próximos à usina e serem um dos principais públicos turísticos de Foz do Iguaçu, atribuíram notas muito próximas das notas atribuídas pelos estrangeiros de outros países, sugerindo que a comunicação de marca da Itaipu está muito mais concentrada nos países onde a usina está localizada.

A quantidade de vezes que o turista visitou o atrativo também mostrou relação com o CBBE, sugerindo que quem já havia visitado o atrativo avaliou melhor todos os itens, especialmente no item Conhecimento de Marca. Em relação à motivação para visitar, houve diferença entre os que foram motivados pela expectativa de qualidade do passeio, que avaliaram melhor o item Lealdade de Marca, demonstrando preferência e mais interesse em visitar o atrativo. Em relação ao gênero, não foi observada variação significativa no $\mathrm{CBBE}$, assim como as demais características do perfil que de forma geral não apresentaram variação significativa entre suas avaliações.

$\mathrm{O}$ item que mais apresentou diferença entre as amostras do lado brasileiro e paraguaio foi o CM5 ("Eu consigo me lembrar da logomarca de Itaipu”). Enquanto no lado brasileiro o item pontuou 3,05, no lado paraguaio a nota foi 3,95. Este fato pode ter relação com o local da entrevista, pois no Paraguai havia um totem com o logotipo à vista, mas também pode ter relação com a marca ser, de fato, mais presente no Paraguai, que por ser menor que o Brasil, tem a Itaipu como um de seus principais símbolos. A amostra do lado paraguaio avaliou mais positivamente praticamente todos os itens, com exceção dos itens IM5 (“Complexo Turístico Itaipu tem um ambiente agradável”) e IM9 (“O Complexo Turístico Itaipu tem boa localização e fácil acesso”), sendo que ambos os itens podem ter relação com a reforma no Centro de Visitantes do lado paraguaio, que dificultou o acesso e não possibilitou um ambiente totalmente adequado às necessidades dos visitantes.

\section{CONSIDERAÇÕES FINAIS}

Buscou-se mensurar o valor de marca do atrativo turístico binacional sob o ponto de vista do consumidor, a fim de averiguar a adequação do instrumento, bem como comparar a percepção de marca pelo público de dois complexos turísticos 
(brasileiro e paraguaio) de um mesmo atrativo, a usina Itaipu Binacional. Utilizou-se uma adaptação do instrumento para medição do CBBE de destinos utilizado por Konecnik (2006) e em constante melhoria através de estudos posteriores (BOO, 2006; KONECNIK; GARTNER, 2007; BOO; BUSSER; BALOGLU, 2009; PIKE et al., 2010, TELES, 2011; KASHIF, SAMSI; SARIFUDDIN, 2015).

Para tanto, conforme método explanado, foi possível cumprir os objetivos do estudo, o qual demonstrou que tanto o CTI lado paraguaio quanto o CTI lado brasileiro apresentaram um alto valor de marca, mas que ficou prejudicado principalmente pela falta de opções gastronômicas, pelo baixo conhecimento da marca, em mais alto grau para o público estrangeiro, e pela baixa identificação da autoimagem do público com a imagem percebida do atrativo. A real representatividade deste item deve ser avaliada, pois em diversos estudos (KONECNIK, 2006; KONECNICK; GARTNER, 2007; TELES, 2011; KASHIF, SAMSI; SARIFUDDIN, 2015) ele e os demais itens propostos por Boo (2006) não faziam parte da dimensão Imagem de Marca.

Outro item que merece estudos mais aprofundados diz respeito à Lealdade de Marca. Mesmo com avaliações baixas na preferência do visitante em relação ao atrativo (LM4) verificou-se haver forte intenção de voltar a visitar e de recomendar aos amigos, o que sugere que a dimensão lealdade de um atrativo turístico pode conter nuances diferentes da lealdade de outro tipo de produto ou serviço, principalmente porque os índices de revisitação e recompra de um atrativo são naturalmente mais baixos, comparados a produtos e serviços de uso frequente.

Esta pesquisa pode corroborar com algumas descobertas realizadas em estudos similares, em especial com o trabalho de Boo, Busser e Baloglu (2009) e Dedeoğlu et al. (2018), pois também evidenciou a forte relação entre a dimensão Conhecimento de Marca e o CBBE. Percebeu-se, assim como nos estudos supracitados, que esta foi a dimensão mais sensível do construto multidimensional.

Uma observação que deve ser considerada pela academia e pelos gestores de marcas de atrativos é que, assim como há relação de causa-efeito entre os atributos funcionais da competitividade e o CBBE em ambos os sentidos (WONG; TEOH, 2015), notou-se certa interdependência entre todas as dimensões, pois alterações em uma dimensão eram percebidas em outras, mostrando que o sucesso ou fracasso em uma 
única dimensão pode afetar a percepção das demais dimensões da marca. Entretanto, esta constatação necessitaria de análise mais aprofundada em estudos futuros.

Apesar dos cuidados em relação à metodologia, algumas limitações se impuseram a este estudo. O questionário, muito extenso, fez com que muitos respondentes não o completassem, bem como a tradução e adequação dos termos pode não ter ficado totalmente adequada a todos os públicos, visto que cada país/região tem particularidades que não puderam ser completamente consideradas. A opção de realizar a pesquisa antes do passeio, mas dentro do espaço físico do atrativo, pode ter causado algum tipo de viés, assim como o fato de o Centro de Recepção de Visitantes do lado paraguaio estar em reforma no período do estudo. Ressalta-se que, apesar de alcançados os objetivos e atingindo grau de confiabilidade interna, este foi apenas um passo a mais para a criação de um instrumento para mensuração do CBBE de atrativos turísticos, e muito ainda há para se avançar. Recomenda-se que, antes de assumir esta escala como válida, sejam feitos outros estudos reaplicando este questionário, a fim de avaliar possibilidades distintas de dimensões e itens, bem como de outras formas de aplicação da pesquisa, a fim de diminuir o viés.

O fato da Itaipu Binacional ter complexos turísticos em dois países permitiu validações do questionário e comparações entre os valores do mesmo atrativo sob pontos de vista de operações diferentes, o que foi bastante distinto. Quanto ao instrumento, convém fazer outros estudos, especialmente em demais atrativos técnicocientíficos, e aprofundar as análises com outras amostras, utilizando técnicas estatísticas mais avançadas em relação à multidimensionalidade, como análise fatorial exploratória e modelagem em equações estruturais.

Convém ainda realizar estudos mais criteriosos sobre a dimensão Imagem de Marca, pois os itens utilizados por Boo (2006) e Konecnik (2006) trouxeram resultados diferentes nesta e em pesquisas anteriores. Também convém realizar testes de agrupamento de cluster para identificar subgrupos dentro da amostra, bem como pesquisar com maior profundidade o real impacto dos itens do perfil socioeconômico que aparentaram influenciar o CBBE.

Como sugestões para a organização, seria conveniente rever a comunicação nos mercados emissores estrangeiros, principalmente na Argentina, principal mercado estrangeiro da região, mas que apresentou CBBE notadamente mais baixo que a média. 
Dedeoğlu et al. (2018) sugerem o uso de mídia tradicional aliada a mídias sociais para criar maior consciência de marca, sobretudo esta última, por apresentar uma comunicação mais rápida e com custos reduzidos. Também convém buscar melhorias e inovações constantes em sua atratividade e qualidade do serviço, pois a baixa avaliação do $\mathrm{CBBE}$ pelos visitantes experientes indica que aqueles que conhecem ou vivem em países economicamente desenvolvidos esperam maiores níveis de atratividade e qualidade para avaliarem a marca mais positivamente. Conforme destacado por Dedeoğlu et al. (2018), entregar experiências surpreendentes é fator fundamental para que os visitantes compartilhem suas experiências e incentivem seus amigos a visitarem, ou seja, a satisfação é fator determinante para o sucesso de uma marca de turismo.

\section{REFERÊNCIAS}

AAKER, D. A. Marcas: brand equity gerenciando o valor da marca. São Paulo: Negócio editora, 1998.

AAKER, D. A; JOACHIMSTHALER, E. Como construir marcas líderes. Porto Alegre: Bookman, 2007.

BARBACENA, H. A. P. A globalização do turismo e a competitividade dos destinos turísticos. 91 p. Dissertação (Mestrado em Economia Portuguesa e Integração Internacional). Lisboa: $\quad$ ISCTE, 2012. Disponível em $\langle$ http://hdl.handle.net/10071/6270>. Acesso em: 23/06/2016.

BARBETTA, P. A. Estatística aplicada às ciências sociais. Florianópolis: Ed. da UFSC, 2011.

BOO, S. Multidimensional Model of Destination Brands: an application of customerbased brand equity. Tese (Doutorado em Hotel Administration). University of Nevada, Las Vegas, USA, 2006.

BOO, S.; BUSSER, J.; BALOGLU, S. A model of customer-based brand equity and its application to multiple destinations. Tourism management. v. 30, n. 2, p. 219-231, 2009.

CHIBIAQUI, R.; HACK NETO, E. Diagnóstico do Customer-based Brand Equity do Complexo Turístico Itaipu - lado paraguaio. In: FÓRUM INTERNACIONAL DE TURISMO DO IGUASSU, 11., 2017, Foz do Iguaçu. Anais... Foz do Iguaçu: Anais do Fórum Internacional do Iguassu, 2018. 
CRESWELL, J. W. Projeto de Pesquisa: métodos qualitativo, quantitativo e misto. 2. ed. Porto Alegre: Bookman Companhia Editora, 2007.

CURY, M. J. F.; RODRIGUEZ, A. G. El desenvolvimiento de actividad turística em la presa hidroeléctrica de Itaipu Binacional. Un territorio em una sociedad transfronteriza. ROTUR. Revista de Ocio y Turismo, n. 4, p. 139-160. Coruña, 2011.

DEDEOĞLU, B. B.; NIEKERK, M. V.; WEINLAND, J.; CELUCH, K. Reconceptualizing customer-based destination brand equity. Journal of Destination Marketing \& Management. p. 1-20, 2018

DIAS, R.; CASSAR, M. Fundamentos do marketing turístico. São Paulo: Pearson Prentice Hall, 2005.

GÂNDARA, J. M. G.; HACK NETO, E.; MANOSSO, F. C. Percepções Turísticas: como a comunidade local representa e simboliza o destino Foz do Iguaçu - PR? In: SEMINÁRIO ANPTUR, 11., 2014. Anais... Ceará: UECE, 2014.

GOMES, M.; LOPEZ, C.; MOLINA, A. A model of tourism destination brand equity: the case of wine tourism destinations in Spain. Tourism Management, v. 51, p. 210$222,2015$.

HAIR, J. F.; ANDERSON, R. E.; TATHAM, R. L.; BLACK, W. C. Análise multivariada de dados. 6. ed. Porto Alegre: Bookman, 2005.

HENZ, A.; CRUZ, J. Qualidade em destinos indutores: Análise dos serviços e equipamentos turísticos de Foz do Iguaçu / PR. Caderno de Estudos e Pesquisas do Turismo, v. 4, p. 77-98, 2015.

IMF. World Economic Outlook: Gaining Momentum? Washington: International Monetary Fund, 2017.

ITAIPU. Usina de Itaipu recebeu mais de 19 milhões de visitantes. 2015. Disponível em: 〈https://www.itaipu.gov.br > Acesso em: 20/03/2016.

Prêmios | Itaipu Binacional. Disponível em: <https://www.itaipu.gov.br/institucional/premios $>$ Acesso em: 05/02/2019.

KAPFERER, J.-N. The New Strategic Brand Management: creating and sustaining brand equity long term. Kogan Page, 2008.

KASHIF, M.; SAMSI, S. Z. M.; SARIFUDDIN, S. Brand equity of Lahore Fort as a Tourism destination Brand. RAE, São Paulo, v. 55, n. 2, p. 432-443, 2015.

KELLER, K. L. Conceptualizing, Measuring, and Managing Customer-based Brand Equity. Journal of Marketing, v. 57, 1993. 
KONECNIK, M. Croatian-based brand equity for Slovenia as a tourism destination. Economic and Business Review for Central and South. Eastern Europe, v. 8, n. 1, 2006.

KONECNIK, M.; GARTNER, W. C. Customer-based brand equity for a destination. Annals of Tourism Research, v. 24, n. 2, p. 400-421, 2007.

KOTLER, P.; KELLER, K. L. Administração de Marketing. 14 ed. São Paulo: Pearson Education do Brasil, 2012.

LA NACIÓN. Negocios en Expo Santa Rita mermarán un 30\% este año. Paraguai, 2015. Disponível em: <http://www.lanacion.com.py>. Acesso em: 20/06/2016.

LASSAR, W.; MITTAL, B.; SHARMA, A. Measuring customer-based brand equity. Journal of Consumer Marketing. v. 12, n. 4, p. 11-19, 1995.

LIMA, A. C. G. Inventário da oferta turística. Brasília: Ministério do Turismo, 2011. Disponível em: <http://www.inventario.turismo.gov.br/invtur>. Acesso em: 20/03/ 2016.

MAlHOtRA, N. K. Pesquisa de Marketing: uma orientação aplicada. 3. ed. Porto Alegre: Bookman, 2004.

MORAES, L. A. DE; GÂNDARA, J. M. G. Midiatização e espetacularização do turismo. Turismo e Sociedade, v. 9, n. 1, p. 1-18, 2016.

PEREIRA, M. G. Artigos científicos: como redigir, publicar e avaliar. Rio de Janeiro: Guanabara Koogan, 2013.

PIKE, S.; BIANCHI C.; KERR, G.; PATTI, C. Consumer-based brand equity for Australia as a long-haul tourism destination in an emerging market. International Marketing Review, v. 27, n. 4, p. 434-449, 2010.

SEABRA, A. L. DE C. A competitividade entre destinos na era digital: Uma análise do potencial das mídias. Turismo e Sociedade, v. 10, n. 3, p. 1-25, 2017.

SIBIREVA, E. Customer-based Brand Equity model (CBBE) for measurement of mice destinations brand performance. Dissertação (Mestrado em Economia). University of Ljubljana, Slovenia, 2014.

SÓRIA, M. A. Z. Usina de Itaipu: integração energética entre Brasil e Paraguai: uma síntese histórica da Itaipu Binacional. Foz do Iguaçu: Editora UFPR, 2012.

SWARBROOKE, J.; HORNER, S. O comportamento do consumidor no turismo. São Paulo: Aleph, 2002.

TELES, M. I. S. O Customer-based Brand Equity do Destino Turístico Foz do Iguaçu. Dissertação (Mestrado em Administração). UFPR, Curitiba, 2011. 
TUOMINEN, P. Managing Brand Equity. Liiketaloudellinen aikakauskirja LTA The Finnish Journal of Business Economics. v. 1, p. 65-100, 1999.

UNWTO. Tourism and the Sustainable Development Goals - Journey to 2030. Madrid: UNWTO, 2017.

VARGAS NETO, A. Mensuração de Brand Equity baseada no consumidor: avaliação de escala multidimensional. Dissertação (Mestrado em Administração). UFRS, Porto alegre, 2003. Disponível em <https://www.lume.ufrgs.br>. Acesso em: 25/03/2016.

VIGNATI, F. Gestão de destinos turísticos: como atrair pessoas para pólos, cidades e países. Rio de Janeiro: Ed. Senac Rio, 2008.

WONG, P. P. W.; TEOH, K. The influence of destination competitiveness on customerbased brand equity. Journal of Destination Marketing \& Management. v. 4, n. 4, p. 206-212, 2015.

YANAZE, M. Y. Gestão de Marketing: avanços e aplicações. São Paulo: Saraiva, 2006.

YOO, B.; DONTHU, N. Developing and Validating a multidimensional customer-based brand equity scale. Journal of Business Research, v. 52, n. 1, p. 1-14, 2001.

YUWO, H.; FORD, J. B.; PURWANEGARA, M. S. Customer-based brand equity for a tourism destination (CBBETD): the specific case of Bandung City, Indonesia. Organizations and Markets in emerging economies. v. 4, n. 1, p. 8-22, 2013.

ZARDO, E. F. Marketing Aplicado ao Turismo. São Paulo: Roca, 2003.

ZEYTONLI, A. H.; DANA, A.; MADADI, B. The customer-based brand equity for sport tourism destinations. Research Journal of Sport Science, v. 3, n. 1, p. 1-7, 2015.

Recebido em: 29-11-2018.

Aprovado em: 30-12-2018.

Versão finalizada para publicação em: 16-03-2019. 